\title{
Entre neocorporativistas e deliberativos: uma interpretação sobre os paradigmas de análise dos fóruns participativos no Brasil
}

SORAYA UARGAS CORTES"

ALFREDO GUGLANO"

\section{Resumo}

Este artigo propõe o debate a respeito dos principais paradigmas a partir dos quais, usualmente, vêm sendo estudadas as propostas de ampliação dos canais de participação dos cidadãos na gestão das políticas públicas, análises que investigam os processos participativos ou desde o prisma dos "arranjos neocorporativos", ou por meio de uma perspectiva baseada na concepção de "democracia deliberativa". Visando este objetivo, o presente texto centra seus interesses na trajetória de duas das principais instâncias participativas que, nas últimas décadas, foram desenvolvidas no Brasil: os orçamentos participativos e os conselhos de políticas públicas. Estas instâncias foram avaliadas levando em consideração, especialmente, quatro elementos a) relações institucionais com os governos; b) perfil dos participantes; c) âmbito decisório e, d) dinâmicas de funcionamento. A partir do estudo destas características, os autores discutem sobre a capacidade dos paradigmas neocorporativo e deliberativo constituírem um modelo analítico consistente para a investigação de estruturas participativas dessemelhantes.

Palavras-chave: Conselhos de Políticas Públicas. Democracias deliberativas. Orçamentos Participativos. Neocorporativismo.

\footnotetext{
* Professora Associada do Departamento e Programa de Pós-Graduação em Sociologia da Universidade Federal do Rio Grande do Sul, pesquisadora do CNPq.

** Professor Adjunto do Departamento e Programa de Pós-Graduação em Ciência Política da Universidade Federal do Rio Grande do Sul, pesquisador do CNPq.
} 
Sociologias, Porto Alegre, ano 12, no 24, mai./ago. 2010, p. 44-75

\section{Introdução}

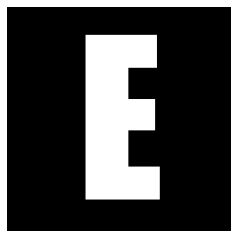

ste artigo trata dos principais fóruns participativos de gestão pública constituídos no Brasil, a partir do final dos anos 1980 do século XX, analisando diferentes modelos interpretativos empregados pela literatura especializada no assunto. O objetivo é identificar qual a contribuição que esses modelos oferecem para a compreensão do papel institucional que os orçamentos participativos e conselhos de políticas públicas desempenham junto aos governos das cidades e estados do país. Além disso, se propõe a discutir as características gerais desses fóruns, de modo a colaborar na construção de teorias de médio alcance que permitam situá-los no contexto institucional e político nacional, superando as descrições de casos tão comuns na análise de experiências participativas.

A literatura aqui analisada é aquela que considera que esses fóruns democratizam a gestão governamental e que se dedica, além da análise empírica, a buscar interpretações gerais sobre o papel institucional que eles desempenham. Como demonstrado anteriormente por Cortes (2005), as análise sobre fóruns participativos podem ser divididas em dois grandes blocos. O primeiro congrega os trabalhos que se mostram céticos sobre as possibilidades de fóruns participativos favorecerem a democratização da gestão pública. O segundo é formado por pesquisadores que acreditam na capacidade dos mecanismos participativos induzirem a democratização do Estado. No presente texto a análise dos orçamentos participativos e dos conselhos de políticas públicas é feita à luz da segunda vertente interpretativa, ou seja, aquela que vê com bons olhos a criação de mecanismos participativos, pois, eles seriam canais importantes de aprimoramento da governança democrática nos diferentes níveis da administração pública

Mesmo compartilhando uma visão positiva sobre os efeitos democratizantes das experiências participativas, as interpretações sobre o papel 
institucional dos fóruns aqui analisadas divergem sobre a natureza desses espaços e dos interesses sociais ali representados. Para uns, os fóruns participativos integrariam a arena pública propiciando a expressão de interesses gerais apresentados pelos movimentos sociais e pelas associações da sociedade civil. De modo contrastante, para outros, os fóruns participativos seriam arranjos neocorporativistas de representação de interesses, incorporando demandas por meio da ação dos grupos de interesse, organizações geralmente nucleadas em torno de pleitos particulares, específicos, não gerais como defendem os primeiros.

As duas perspectivas consideram que a participação tem efeitos positivos para a democratização da gestão pública, mas, o artigo argumenta que elas oferecem contribuições distintas para as experiências participativas em orçamentos participativos e em conselhos de políticas públicas, tendo em vista características essenciais diferentes que eles apresentam. Assim, uma interpretação sobre o papel institucional dos fóruns pode ser adequada para um tipo de experiência e não para o outro. De modo a demonstrar isso, examinam-se as seguintes características dessas instâncias: a) relações institucionais com os governos; b) perfil de seus participantes; c) questões sobre as quais decidem; e, d) suas dinâmicas de funcionamento.

O artigo inicia com a exposição sintética das duas interpretações contrastantes sobre o papel institucional dos fóruns participativos - vistos como arenas deliberativas nas quais interesses gerais são representados ou como arranjos neocorporativistas. A partir disso, apresenta as características mais destacadas dos orçamentos participativos e conselhos de políticas sociais, buscando verificar a sua adequação aos modelos de interpretação anteriormente destacados.

Com este estudo, nossa intenção é contribuir para o avanço na análise das novas experiências de gestão de políticas públicas no país, por meio da elaboração de modelos de interpretação adequados à variedade de práticas participativas que vêm se desenvolvendo nas últimas décadas. 


\section{O debate sobre o papel institucional dos fóruns participativos}

No debate atual sobre a formulação e execução de políticas públicas, várias vertentes teóricas rivalizam a construção de um modelo interpretativo hegemônico, capaz de traduzir as transformações mais recentes geradas nas estruturas estatais (FARIA, 2003; MULLER; SUREL, 2002; SOUZA, 2006). No que tange às experiências participativas de gestão pública, autores inspirados em duas formas distintas de análise da participação política - a deliberacionista e a neocorporativista - têm procurado compreender o papel institucional dos fóruns participativos constituídos, marcadamente no Brasil, desde o final dos anos 1980 do século passado.

A perspectiva de análise mais influente sobre os processos participativos brasileiros, durante os anos 90 do século passado, é inspirada nas teorias que utilizam centralmente o conceito de democracias deliberativas, termo caro não apenas aos analistas, como também aos defensores dessas experiências.

O ponto de partida para o debate sobre a perspectiva deliberacionista é a obra de Habermas e sua defesa da importância da esfera pública enquanto um espaço de debate e negociação, envolvendo o Estado e a sociedade civil. A esfera pública não seria nem uma instituição, nem uma organização, consistindo mais bem numa rede comunicacional - Habermas chega a chamar de estrutura comunicacional - na qual a ação social é produzida a partir do diálogo (HABERMAS, 1997).

Articulado com o conceito anterior, a ideia de democracia deliberativa parte do pressuposto de que o processo de política deliberativa constitui o núcleo da democracia. A formação democrática da opinião, gerada por meio de processos comunicativos, representaria então a meIhor forma de influenciar a racionalização discursiva das decisões de um governo (HABERMAS, 1997). 
Dando continuidade ao seu projeto de renovação da teoria democrática, Habermas considera que o conceito de democracia deliberativa se desenvolve a partir da superação das perspectivas de análise republicana e liberal. Explicitando esta caracterização, o citado autor enfatiza que sua proposta de democracia entende o processo democrático de maneira mais forte do que a perspectiva liberal, contudo, não tão radicalizada quanto à perspectiva republicana.

Nesse sentido, o reconhecido pensador alemão se esforçaria para resgatar alguns preceitos das teorias liberal e republicana, de forma a aperfeiçoar sua concepção de sistema político democrático. Desde a ótica liberal, quiçá um dos pontos mais importantes do resgate habermasiano seja a necessidade de assegurar limites na articulação entre Estado e Sociedade, isto é, barrar qualquer perspectiva insurrecional dos processos de debate público de modo a garantir a legitimidade dos representantes políticos escolhidos pelos canais eleitorais. Já do prisma republicano se destaca a perspectiva de organização de uma esfera pública como uma arena que permita articular, num mesmo espaço político, representantes da sociedade civil e da sociedade política, ampliando um modelo de gestão governamental baseado quase exclusivamente na representação parlamentar.

A partir dessa complexa articulação, Habermas elabora sua teoria política discursiva visando um objetivo diferenciado, o desenvolvimento de espaços públicos autônomos da sociedade civil nos quais seja possível incrementar a racionalidade comunicativa, fortalecendo a solidariedade enquanto uma alternativa de integração e regulação social (HABERMAS, 1995).

Com o ingresso de outros pensadores no debate sobre a democracia deliberativa, os preceitos elaborados originalmente por Habermas passaram por um processo de crítica e, em alguns casos, sofreram certa radicalização. Sintetizando uma querela ainda inacabada, é possível afirmar que o centro das divergências estaria precisamente na caracterização das 
Sociologias, Porto Alegre, ano 12, no 24, mai./ago. 2010, p. 44-75

dimensões de soberania popular que poderiam ser almejadas a partir da esfera pública e, consequentemente, a polêmica sobre a necessidade de complementação dos espaços discursivos por meio de instâncias efetivas de deliberação popular ${ }^{1}$.

O debate interno retrata a vitalidade da corrente e o expressivo número de acadêmicos e ativistas políticos que a compõem (DAGNINO, 2002; EVANS, 2003; FEDOZZI, 1997; FUNG; WRIGHT, 2001; GOHN, 2001; GUGLIANO, 2008; JACOBI, 2002; NAVARRO; GODINHO, 2002; AVRITZER, 2000) ${ }^{2}$. Esses autores podem ser classificados conjuntamente porque compartilham a visão de que, coexistindo com mecanismos tradicionais de participação política das democracias representativas, esses fóruns podem propiciar deliberação ampla e constituem novas formas de exercício coletivo do poder político. Além disso, consideram que tais fóruns poderiam estar indicando a formação de outro tipo de democracia em contraposição às formas tradicionais de democracia representativa.

Em um amplo universo de autores, destacam-se os estudos de Avritzer (2000) e Santos (1999) dentre aqueles que mais densamente analisaram as potencialidades das instâncias participativas, muito especialmente, dos orçamentos participativos. Enquanto o primeiro argumenta que a auto organização da sociedade civil e fóruns participativos podem articular-se na formação de uma versão radical de democracia deliberativa, o segundo chama atenção para as possibilidades de reinvenção da democracia, em um projeto no qual tanto o Estado quanto a sociedade civil renovariam seus papeis sociais.

1 Uma análise interessante que aborda algumas das principais visões sobre a idéia de democracia deliberativa é desenvolvida por Faria (2000).

2 Embora essa vertente de estudos tenha sido muito influente durante a década de 1980 no Brasil, diversas análises críticas têm enfatizado os limites dos instrumentos teórico-conceituais que estas oferecem à análise da natureza do Estado e da sociedade civil, bem como de fóruns participativos (BAKER, 2000; BONFIM; FERNANDES, 2004; LAVALLE, 2003; SILVA, 2004). 
Embora nem todos os autores adotem integralmente um modelo teórico de inspiração habermasiano, centrado na caracterização de democracia deliberativa, é possível identificar a influência dessa perspectiva teórica em alguns dos trabalhos seminais deste grupo (AVRITZER, 1997; COSTA, 1997, 1999). Desde esta ótica, os movimentos sociais que ingressaram nas arenas políticas latino-americanas e nos fóruns participativos, representaram núcleos de tematização de interesses gerais na órbita da esfera pública contrastando, nesse sentido, com grupos corporativos - sindicatos, partidos políticos - que defendiam interesses particulares (COSTA, 1994; COSTA, 1997).

A participação dos movimentos sociais nos processos de democratização latino-americanos colocaram na ordem do dia uma nova forma de relação entre Estado e sociedade, fato que implicou na introdução de experimentalismo na própria esfera estatal (GUGLIANO, 2008; SANTOS; AVRITZER, 2002). A ideia de inevitabilidade da representação em sociedades complexas, com grandes populações, estaria sendo problematizada pelo aumento da diversidade étnica, cultural e de interesses envolvidos nos arranjos políticos contemporâneos. A articulação entre democracia representativa e deliberativa ofereceria respostas mais promissoras na defesa de interesses e identidades subalternas, sendo que o êxito de experiências participativas estaria relacionado "à capacidade dos atores sociais transferirem práticas e informações do nível social para o nível administrativo" (SANTOS; AVRITZER, 2002, p. 54).

A abordagem que atribui aos fóruns participativos características neocorporativistas é inspirada, por sua vez, na revisão dos estudos sobre o tema a partir, principalmente, das elaborações desenvolvidas por Schmitter (1974). De acordo com este autor, a principal característica do corporativismo estatal moderno é a associação entre grupos de interesse e setores dirigentes do Estado. O corporativismo seria um sistema no qual o Estado 
permitiria a formação de um conjunto de instâncias de representação de interesses sociais, nas quais participariam determinadas organizações, criadas ou licenciadas pelo Estado, que teriam o monopólio dessa representação.

Nesse arranjo, os dirigentes estatais manteriam certo controle sobre a seleção de lideranças e demandas a serem colocadas nas agendas de discussão das instâncias corporativistas. Ao mesmo tempo, as lideranças reforçariam sua posição de autoridade frente aos membros de suas organizações, em função do prestígio gerado pelo atendimento das suas demandas.

Na sua origem, houve uma tendência em direcionar o conceito de neocorporativismo estatal, especialmente, para o estudo da ação dirigente do Estado nas relações entre o capital e trabalho, assim como para soluções concertadas dos conflitos envolvendo interesses do mercado econômico e da regulação estatal (ALMEIDA, 1998; KELLER, 1998; OFFE, 1992). Contudo, a perspectiva neocorporativista se estendeu gradativamente ao conjunto de políticas públicas, especialmente em termos de uma alternativa de análise ao pluralismo 3 (RIVERA, 1995; LIJPHART, 2000).

O emprego do conceito de núcleos neocorporativos ou formas neocorporativas de representação de interesses, combinado ao uso dos conceitos hirschmanianos de "voz" e "saída", oferece elementos para a construção de generalizações sobre as condições institucionais e políticas que levaram a constituição dos fóruns e que explicam, ao menos em parte, o seu funcionamento. O conceito de "voz", proveniente do trabalho de Hirschman (1970), representa um recurso analítico importante, para o exame da relação entre participação e gestão pública, na medida em que estabelece uma ligação entre a liberdade dos membros para influenciar o comportamento de uma organização - um governo, uma área de política pública, por exemplo - e o nível de eficiência em essa organização opera. Segundo Hirschman, existiriam três maneiras de solucionar processos que

3 Pluralismo é aqui entendido como uma corrente que enfatiza a autonomia dos grupos de interesse na dinâmica de definição das políticas públicas estatais. 
envolvem conflitos de interesse: a "saída", típico mecanismo de mercado por meio do qual o cidadão desiste de comprar ou de usar um determinado produto, serviço ou, até mesmo, abandona a organização a qual mantém filiação; a "voz", enquanto um mecanismo político que possibilita que ele proteste, expresse oposição, preferências, exerça influência; e a "lealdade", comportamento adotado por aqueles que se dispõem a abrir mão de suas preferências em função de determinados compromissos de fidelidade.

Consequentemente, os fóruns participativos poderiam se constituir em "organizações intermediárias" neocorporativas, no sentido atribuído ao termo por Streeck e Kenworthy (2003, p. 15-17), ou seja, instâncias não só reconhecidas como também, muitas vezes, embrionadas por iniciativa dos próprios governos, os quais exercem sobre elas forte influência no sentido de estabelecer a intermediação de interesses entre os diversos atores sociais. Entretanto, os fóruns participativos, no entanto, permaneceriam em última instância livres para recusar cooperação com os governos, mesmo que estes colaborem para resolver seus problemas organizacionais.

A participação de representantes de diferentes grupos de interesses nos fóruns, vistos como organizações intermediárias, pode não significar atribuição de "licenciamento" estatal às associações - ou sindicatos -, tal como ocorre no corporativismo estatal, mas, sem dúvida, tem o caráter de "reconhecimento" e, portanto, de legitimação desses representantes frente aos membros das respectivas associações, como ocorre no neocorporativismo ou corporativismo societal. Desse modo, os representantes são vistos como líderes capazes de influenciar políticas. Mais do que isso, muitas vezes, os representantes podem comprometer-se em favorecer o cumprimento de decisões ou até mesmo podem tornar-se responsáveis, junto com suas organizações, pela execução das políticas ${ }^{4}$.

4 Sobre o tema, sugerimos consultar também o conceito de "corporativismo de bem-estar" (welfare corporatism), empregado por Mishra (1984) e Williamson (1989), a partir do qual a ênfase do debate recai sobre os profissionais e outros produtores de bens e serviços no âmbito do Estado de Bem Estar Social. 
Sociologias, Porto Alegre, ano 12, no 24, mai./ago. 2010, p. 44-75

A vertente de interpretação que considera que os fóruns participativos seriam núcleos neocorporativos congregam um número menor de autores (BOSCHI, 1999; SCHMIDT, 2001, SANTOS, 2001). De um modo geral, os cientistas sociais que destacam o elemento neocorporativo dos processos participativos tendem a identificar esses organismos como formas de complementação da democracia representativa, sublinhando sua capacidade de aperfeiçoar a governança, assim como desenvolver a accountability. Tais autores não defendem formas de democracia participativa em contraposição à democracia representativa. Além disso, em muitos desses estudos existe a tendência a considerar que o participante é um defensor de interesses particulares na condição de habitante de determinada região ou de usuário ou beneficiário de políticas públicas.

Um dos pioneiros nessa perspectiva analítica foi Boschi (1999), ao afirmar que os conselhos de políticas públicas e de direitos sociais freqüentemente constituiriam núcleos neocorporativos, nos quais diferentes interesses seriam representados sob a supervisão de órgãos públicos ou associações locais sólidas. Nesses fóruns, poderiam se estabelecer novas maneiras de articulação entre as formas tradicionais de decisão de gestores públicos e a representação dos interesses societais. A tendência seria estabelecer um equilíbrio entre os esforços para autonomia, por parte dos gestores, e para a aproximação e penetração por parte das clientelas. Essa estabilidade seria importante para entender as condições subjacentes para produção de políticas, como inclusive para a mudança ou alteração do curso das políticas públicas existentes.

Schmidt (2001) também considera que as instâncias participativas brasileiras teriam caráter neocorporativista, ao ressaltar o que chama de consequências positivas e negativas que produzem para o desenvolvimento da democratização. Segundo o mesmo, os mecanismos participativos representariam uma forma de delegação de responsabilidades por parte 
do Estado para com as organizações sociais o que, consequentemente, geraria uma co-responsabilização pelo processo.

Santos (2001), por sua vez, chama atenção para a hipótese de que, no Brasil, embora a arena decisória burocrática não tenha sofrido mudanças no período democrático, haveria a incorporação de atores estratégicos anteriormente excluídos através dos fóruns participativos das áreas sociais e do meio ambiente (SANTOS, 2001). Para a autora, a partir das administrações de Fernando Henrique Cardoso (1995-2002), haveria um padrão bifurcado de relacionamento com os atores sociais, sendo que as decisões sobre política econômica seriam tomadas em contextos de insulamento burocrático. Em relação às políticas sociais e de meio ambiente, teriam sido construídas "estruturas de decisão, com participação institucionalizada dos grupos afetados por essas políticas" (SANTOS, 2001, p. 746). Em contextos de países em desenvolvimento - ela argumenta -, aqueles com estruturas socioeconômicas acentuadamente desiguais, formas de representação de interesse, tais como as neocorporativas, poderiam abrir o espaço decisório para grupos sociais sem capacidade de se fazer representar adequadamente na esfera pluralista (SANTOS, 2001, p. 756).

Nesta seção foi possível verificar que os estudos que consideram que os fóruns participativos brasileiros promovem a democratização da gestão pública podem ser agregados em dois grupos. Apesar das divergências, ambos consideram que o desenho institucional dos fóruns favorece a emergência de um novo tipo de processo decisório que pode, ou abarcar os interesses gerais, na visão dos adeptos às teorias democráticodeliberativas, ou incluir novos grupos de interesses seccionais, conforme os simpatizantes das teses neocorporativistas.

Todavia, ainda é necessário examinar as características institucionais dos dois tipos de fóruns para verificar quais os interesses que podem estar ali representados. Além disso, é necessário verificar se eles têm um papel 
Sociologias, Porto Alegre, ano 12, no 24, mai./ago. 2010, p. 44-75

relevante no processo de decisão política geral dos governos ou se decidem apenas sobre questões secundárias nas suas agendas; se as decisões tratam de dinâmicas macropolíticas ou mais bem tratam de problemáticas setoriais.

\section{O papel institucional dos fóruns participativos brasileiros: orçamentos participativos e conselhos de políticas públicas}

Os dois tipos de fóruns mencionados apresentam antecedentes semelhantes: as experiências participativas dos anos 70 e 80 (CASTRO, 1988; COSTA, 1997; FERREIRA, 1991; SOUZA, 2001, p. 161-163). Governos municipais nos Estados de São Paulo, Santa Catarina, Minas Gerais e Rio Grande do Sul criaram conselhos, centros comunitários em distritos e desenvolveram formas de consulta popular ou de usuários de serviços nas áreas de saúde, desenvolvimento urbano, política ambiental e em processos de decisão sobre o orçamento ${ }^{5}$.

Os orçamentos participativos tornaram-se conhecidos em função, principalmente, aos casos de Porto Alegre e Belo Horizonte que tiveram início em 1989 e em 1993, respectivamente. Ambas as experiências iniciam com a vitória do candidato do Partido dos Trabalhadores (PT) e permanecem em funcionamento até os dias de hoje, inclusive após a derrota, em 2004, em Porto Alegre, da coalizão de esquerda que o havia instituído. Porém, antes destas cidades, registraram-se ensaios de participação nos debates sobre os orçamentos públicos em cidades como Lages (1976-1981), em Santa Catarina; Vila Velha (1983-1986), em Goiás, e Pelotas (1984-1985), no Rio Grande do Sul; para ficar apenas em alguns exemplos (GUGLIANO et. al., 2008).

5 Essas experiências foram bem documentadas pelo Instituto PÓLIS que produziu um conjunto significativo de pesquisas que analisam diversas experiências de participação (SOUZA, 2001, p. 163). 
Desde 1990, experiências de orçamento participativo se disseminaram pelo país. O Instituto PÓLIS avalia que, entre 1989 e 2004, pelo menos 261 cidades de 23 estados brasileiros criaram processos que envolveram participação da população nas decisões sobre a alocação de recursos orçamentários (PÓLIS, 2006). Em 2005, na Região Metropolitana de Porto Alegre, em 16 de suas 31 cidades havia mecanismos de participação na decisão sobre os orçamentos municipais (CORTES, 2005). Em 2007, foi criada a Rede Brasileira de Orçamento Participativo que congrega 42 municipalidades (RBOP, 2010). Há ainda casos de orçamentos participativos que se realizaram em nível estadual, como no Rio Grande do Sul, Pernambuco, Acre e Pará (CORTES, 2003; LUBAMBO; COELHO, 2005; Governo do Estado do Pará, 2010).

Cada uma dessas experiências tem suas próprias características. São grandes as diferenças em escala, em termos da população a ser envolvida e do território abrangido, como também existem enormes variações em termos de cultura política e de tradições político-institucionais de cada localidade atingida. No entanto, é possível identificar alguns elementos de seus desenhos institucionais que são recorrentes o suficiente para que possam ser identificados como orçamentos participativos.

O primeiro deles se refere à origem da iniciativa de criação dos fóruns. A Constituição Brasileira estabelece que elaboração de propostas orçamentárias é de competência exclusiva do Poder Executivo (Brasil, 1988, art. 165). Assim, todos os processos de orçamentação participativas são necessariamente criados por iniciativa dos dirigentes governamentais. Assim, a influência dos gestores governamentais em todo o processo é forte, na medida em que, frente à ausência de uma regulamentação nacional - algo semelhante aos princípios constitucionais que norteiam a disseminação dos conselhos -, a própria existência do processo depende do Poder Executivo. 
Outras três características comuns se referem; a) aos tipos de participante a serem envolvidos, b) as questões que mais frequentemente entram em suas agendas para serem debatidas e decididas e c) aos aspectos mais gerais e recorrentes de sua dinâmica de funcionamento. Os participantes potenciais são todos os cidadãos em idade eleitoral da cidade ou do estado ${ }^{6}$, mas, conforme Dias (2002) e Silva (2001), a maioria daqueles que se envolvem são oriundos das áreas mais pobres dos municípios. As decisões tratam majoritariamente da alocação de despesas de capital e, por vezes, de despesas correntes. No entanto, as proporções de recursos orçamentários em discussão podem variar bastante em cada caso (MARQUETTI, 2008).

A dinâmica de funcionamento dos orçamentos participativos passa, diretamente, pela vontade política do Executivo. Não obstante, tal definição é, na prática, resultado de um acordo entre a proposição inicial dos governantes e os representantes da sociedade civil envolvidos. Uma vez iniciado o processo, geralmente os regimentos dos orçamentos participativos permitem que os próprios participantes possam redefinir as regras que guiam os trabalhos. Ao ser alcançado um acordo, a agenda de debates e o cronograma das atividades se transformam em informações públicas. Tanto os participantes potenciais quanto aqueles que, de fato, se envolvem com os orçamentos participativos, podem se preparar para os debates e acompanhar as decisões que são tomadas.

Os fóruns podem combinar mecanismos de participação direta e indireta. A participação direta aconteceria, principalmente, no nível dos bairros e das temáticas, no caso dos processos municipais; ou de distritos e cidades no de orçamentos participativos estaduais. Já a participação indireta ocorreria, especialmente, na eleição de delegados e representantes em fóruns de coordenação dos processos participativos nos mais diferen-

6 Estudos mostraram uma variação marcante entre as cidades e estados no que se refere a capacidade organizativa, nível de ativismo político, nível educacional e gênero dos participantes (SOUZA, 2001; WAMPLER, 2000; NAVARRO, 1997; SILVA, 2001). 
tes níveis. Em Porto Alegre, por exemplo, a participação direta se dá nas assembleias regionais e temáticas e a participação indireta nos fóruns de delegados e no conselho do orçamento participativo. De maneira semeIhante, nos processos participativos estaduais também poderiam existir a combinação entre espaços participativos diretos, assembleias nas cidades ou distritos, e indiretos. Esta combinação foi concretizada em várias experiências, como no caso do orçamento participativo gaúcho (1999-2002).

No nível distrital, nos processos municipais, e no nível das cidades, nas experiências estaduais, o orçamento é discutido em encontros ou assembleias públicas. Esses encontros, em geral, têm a presença de ativistas dos movimentos sociais, moradores das diferentes regiões da cidade, representantes governamentais e políticos. Eles procuram estabelecer as preferências e eleger os delegados que participarão dos níveis superiores de deliberação. Delegados de todos os distritos e regiões negociam as prioridades em conjunto e, posteriormente, verificam se o que foi acordado está de fato sendo cumprido. Estes delegados, muito frequentemente, têm fóruns específicos nos quais as políticas deliberadas nas assembleias são aprimoradas, assim como são responsáveis pela eleição dos componentes da principal instância de coordenação do processo, chamada na maioria das vezes de Conselho do Orçamento Participativo.

Embora existam processos de votação abertos para delegados ou mesmo para todos os eleitores da região abrangida (participantes potenciais), uma característica distintiva dos orçamentos participativos, em relação outros tipos de participação na definição de orçamentos públicos, é o direito à voz. Os participantes podem expressar suas preferências durante encontros desenhados para fixar prioridades de gastos.

Assim, considerando as relações estabelecidas entre as experiências de orçamentos participativos, pode-se afirmar que eles se constituem em arenas onde assuntos de interesse público são discutidos. É adequada, 
portanto, a interpretação da vertente de estudos que afirma que esses fóruns representam, na órbita da esfera pública, núcleos de tematização de interesses gerais, nos quais atores sociais estariam transferindo práticas e informações do nível social para o nível político-administrativo.

Na maioria dos casos, os orçamentos participativos estão abertos a todos os cidadãos, mas, os participantes mais assíduos são, geralmente, ativistas dos movimentos sociais urbanos. De acordo com a mesma vertente interpretativa, os movimentos sociais, devido aos seus padrões organizacionais específicos e a sua inserção no tecido social, podem superar o modelo corporativo tradicional no qual grupos de interesses trazem para as arenas públicas demandas particulares.

A criação de orçamentos participativos depende de um ato de vontade do Poder Executivo por determinação constitucional, por isso, as regras de funcionamento dos fóruns, em boa medida, são o resultado de decisão governamental. Neste caso, são os próprios decisores (decision makers) que estabelecem que os cidadãos devam participar na definição da proposta orçamentária e decidem o desenho institucional do processo participativo a ser implementado.

Não obstante, a capacidade de controle dos gestores governamentais fica limitada pelo caráter público das instâncias de debate orçamentário e pelo papel que lhes é atribuído pelo regulamento decidido de forma consensual. No caso de Porto Alegre, somava-se a isso a visão de que estava se constituindo uma instância autônoma da sociedade civil e que, portanto, a regulamentação de seu funcionamento somente poderia ocorrer por meios dos próprios canais internos de deliberação. O paradigma porto-alegrense foi seguido em outros processos participativos municipais, nos quais, anualmente, as regras de funcionamento são aprovadas no conselho do orçamento participativo ou nas assembleias de base. 
Desse modo, como as regras de funcionamentos são o resultado de acordos consensuais, de fato é possível que atores sociais transfiram práticas e informações da esfera social para a político-administrativa. Mesmo considerando que as decisões tomadas se referem a uma parcela limitada do orçamento, elas afetam a todas as áreas da administração pública, favorecendo a construção de consensos nos quais cada grupo de interesse precisa levar em conta as demandas dos outros participantes.

No entanto, seu caráter pouco institucionalizado, se comparado aos conselhos de políticas públicas, os torna mais vulneráveis frente às mudanças no comando do Poder Executivo e, portanto, é menor a tendência de que a orçamentação participativa torne-se um mecanismo generalizado na gestão pública do país. Paradoxalmente, a mesma liberdade institucional, no sentido de criar regras próprias de funcionamento, que oferece aos gestores uma oportunidade única de exercer experimentalismos na esfera governamental (SANTOS; AVRITZER, 2002, p. 54), também acaba se transformando num Calcanhar de Aquiles na hora de garantir a continuidade dos processos participativos diante das mudanças eleitorais dos governos.

O outro tipo de fórum aqui analisado, os conselhos de políticas públicas, encontra seus antecedentes mais remotos nas áreas de educação e de previdência social. Os primeiros conselhos municipais de educação foram criados no século XIX (WERLE, 1998). Na área da previdência social havia representantes de trabalhadores em órgãos administrativos colegiados - Caixas e Institutos de Aposentadoria e Pensões - criados nas décadas de 20 e 30 do século passado (MALLOY, 1977).

No caso brasileiro, os conselhos de saúde, criados pela Lei 8.142 de 1990 (Brasil, 1990), tornaram-se o paradigma que inspirou a constituição de conselhos em outras áreas. A lei estabeleceu que conselhos de saúde fossem organizados nos níveis federal, estadual e municipal de governo. Sua rápida disseminação está associada ao processo de descen- 
tralização promovido pelo governo federal na área de saúde. A indução positiva para o estabelecimento dos fóruns estava no fato da transferência de recursos financeiros federais para os níveis subnacionais de governo estar condicionada, entre outras coisas, à constituição desses organismos (CORTES, 1995). Em 2001, 98\% das municipalidades - 5.426 de 5.506 cidades - e, a partir do final de 2005, todas as cidades tinham um conselho de saúde (Ministério da Saúde, 2006).

Mesmo que não sejam tão difundidos como na área de saúde, durante o fim do século passado e o início do atual, conselhos de políticas públicas foram criados em praticamente todas as áreas (BULHÕES, 2002; CARVALHO, 1998; CORTES, 1995; DAGNINO, 2002; RAICHELES, 2000; SANTOS JUNIOR, 2001; TATAGIBA, 2002). Existem conselhos nas áreas de emprego e renda, assistência social, desenvolvimento rural, educação, meio ambiente, planejamento urbano, segurança pública, combate a drogas, entre outras. Há conselhos que tratam da garantia de direitos de crianças e adolescentes, dos negros, dos índios, das mulheres, dos portadores de deficiências e patologias, dos idosos, entre outros.

As diferenças entre esses tipos de conselhos são mais acentuadas do que entre os diversos tipos de orçamentos participativos. As variações são principalmente associadas ao arcabouço institucional de cada área de política pública; à cultura política e às tradições políticas de cada região ou cidade; às posições que os dirigentes municipais e estaduais; e a existência ou não em cada área de política pública de uma policy community interessada no fortalecimento de alianças ou coalizões que possam influenciar os processos de decisão política governamental. Mesmo assim, o desenho institucional desses fóruns apresenta uma base comum. Durante a década passada, a maioria das áreas de políticas sociais sofreu um processo de descentralização de recursos financeiros e de funções do nível federal para os subnacionais de governo. Este foi o caso nas áreas de 
saúde, de assistência social, de geração de emprego e renda, de educação fundamental e de desenvolvimento rural, entre outros.

Um conjunto de normas legais - tais como a Constituição de 1988, emendas constitucionais e leis federais - e atos administrativos - ministeriais e dos próprios conselhos - criaram fóruns e estabeleceram quem deveriam ser seus participantes. Por exemplo, a nova Constituição estabeleceu a "participação da população" na área de assistência social e "da comunidade" no sistema de saúde (Brasil, 1988, art. 204/II; art. 198/III). As leis que regulam a organização dos sistemas de saúde e de assistência social (Brasil, 1993, Lei 8.742; Brasil, 1990, Lei 8.142) estabeleceram que conselhos devessem ser criados nos níveis federal, estadual e municipal de gestão.

Os participantes dos conselhos também foram definidos por lei ou por normas administrativas. Na área da saúde, metade dos membros é formada por representantes de usuários, a outra metade é composta por conselheiros oriundos de organismos governamentais e de entidades de profissionais de saúde e de prestadores de serviços (Brasil, 1990, Lei 8.142). Na área de assistência social, metade dos conselhos é formada por representantes governamentais e a outra metade por conselheiros provenientes de entidades da sociedade civil, representando usuários, profissionais da área e prestadores de serviços (Brasil, 1993, Lei 8.742). $\mathrm{Na}$ área de trabalho e emprego, os conselhos são tripartites, compostos pro representantes governamentais, dos empregadores e dos empregados (CODEFAT, 1995, Act no 80). Esses fóruns são formados por representantes governamentais e da sociedade civil e grupos sociais participantes são diretamente interessados naquela área de política pública específica.

Assim, são várias as características contrastantes com os orçamentos participativos que podem ser elencadas. Os últimos são abertos a todos os cidadãos e mesmo seus participantes mais assíduos, os ativistas dos movimentos sociais, podem ter interesses em distintas áreas de políticas 
públicas, enquanto os conselhos congregam participantes especializados em determinadas áreas.

Outra diferença marcante é que os conselhos são altamente institucionalizados enquanto os orçamentos participativos não o são. Os conseIhos fazem parte da estrutura administrativa das áreas de política pública a que estão vinculados. Esse nível alto de institucionalização se expressa nas variações de conteúdo das agendas e nos diferentes tipos de decisão que os conselhos podem tomar em cada área de política pública. Por exemplo, enquanto na área de trabalho e emprego, eles decidem sobre os tipos de cursos de qualificação profissional que serão financiados com recursos públicos, na área de assistência social eles definem quais os provedores privados de serviços assistências estão aptos, de acordo com os critérios legais, a receber, ou continuar recebendo, recursos públicos. As agendas dos conselhos, as questões sobre as quais eles têm poder para decidir, e o seu papel institucional são modelados por regras pré-estabelecidas e pelas necessidades criadas pelas características institucionais de cada área.

As linhas gerais da dinâmica de trabalho dos conselhos também são determinadas por regras legais e administrativas. Embora o seu detalhamento seja definido de forma consensual ou, em muitos casos, imposto pelos gestores, a estrutura geral - no que tange aos tipos de participantes, competência do fórum na área, por exemplo - não está aberta para discussão. Além disso, em contrate com a dinâmica de funcionamento dos orçamentos participativos, na qual o que será discutido é definido no início de cada processo anual, no caso dos conselhos a agenda está permanentemente aberta para as novas políticas, programas ou ações produzidas pelos gestores públicos.

Diferentemente dos orçamentos participativos que articulam mecanismos de democracia direta e representativa, os conselhos são compostos exclusivamente por representantes. A participação direta somente é possível em algumas cidades em que foram criados conselhos distritais, 
contudo, esses conselhos não têm função institucional definida pela normatização legal e administrativa nacional. Participantes nos conselhos de âmbito federal, estadual e municipal são eleitos ou indicados pelas organizações ou parcela da população que representam; ou inclusive instituídos pelos gestores em localidades nas quais as elites políticas controlam praticamente todos os aspectos da dinâmica política municipal.

A maioria dos conselhos tem encontros regulares, embora alguns estudos demonstrem que, em diversos casos, eles não realizam reuniões públicas (CORTES, 2005; IBGE, 2004). Isso ocorre quando as autoridades municipais criam conselhos formalmente, com o único objetivo de obter recursos financeiros federais.

Os conselhos usualmente têm um núcleo diretivo, habitualmente eleito pelos participantes, de acordo com o estabelecido pelo regimento interno de cada fórum. Mesmo quando as autoridades governamentais não coordenam o fórum, elas têm forte influência sobre a formação de suas agendas. Não obstante, os gestores podem oferecer ou retirar a infraestrutura que viabiliza o bom funcionamento dos conselhos. Alguns têm apoio técnico e administrativo oferecido pelas autoridades municipais, estaduais e federais. Por exemplo, os conselhos municipais de saúde geralmente recebem esse tipo de suporte, em contraste com os conselhos de educação fundamental (CORTES, 2005). Embora sejam frequentes as decisões tomadas de modo consensual, em vários casos as discussões levam a processos de votação. Isso ocorre principalmente nas cidades maiores, especialmente nas capitais, e nos conselhos estaduais e federais.

Portanto, em que pesem as diferenças que existem no modo de funcionamento dos conselhos de diferentes áreas de políticas públicas e mesmo em uma mesma área, particularmente ao nível municipal, é possível analisá-los tendo em vista suas características comuns. Assim, pode-se afirmar que a interpretação oferecida por aqueles que consideram que as experiências participativas brasileiras constituem núcleos neocorporati- 
vos, nos quais diferentes interesses são representados, é a mais adequada para entender o papel institucional dos conselhos de políticas públicas.

Nesses espaços institucionais, interesses que antes não tinham oportunidade de se manifestar, são colocados frente a gestores públicos que necessitam - de algum modo - encontrar respostas para novos tipos de demandas sociais. São fóruns altamente institucionalizados, organizados e regulados por regras legais e administrativas estabelecidas em cada área de política pública e seus participantes representam grupos de interesses específicos dessas áreas. O quadro é o resultado sintetizado da análise empreendida nesta seção do artigo. 


\begin{tabular}{|c|c|c|}
\hline Características & Orçamentos Participativos & $\begin{array}{c}\text { Conselhos de Políticas } \\
\text { Públicas }\end{array}$ \\
\hline Relação com os governos & $\begin{array}{l}\text { - criados pelo Poder Executivo } \\
\text { municipal ou estadual; } \\
\text { - dependem do gestor público } \\
\text { que o criou para a definição } \\
\text { de seu desenho institucional, } \\
\text { para o seu funcionamento e } \\
\text { manutenção; }\end{array}$ & $\begin{array}{l}\text { - criados por um conjunto } \\
\text { de regras legais - tais como a } \\
\text { Constituição, emendas cons- } \\
\text { titucionais e leis federais - e } \\
\text { atos administrativos - ministe- } \\
\text { riais ou dos conselhos federais; } \\
\text { - dependem do gestor público } \\
\text { do nível de gestão em que se } \\
\text { encontram para o seu funciona- } \\
\text { mento e manutenção; }\end{array}$ \\
\hline $\begin{array}{l}\text { Tipos de } \\
\text { participantes }\end{array}$ & $\begin{array}{l}\text { - os participantes potenciais } \\
\text { são todos os cidadãos do } \\
\text { município ou do estado, mas a } \\
\text { maior parte dos participantes } \\
\text { provêm de regiões urbanas } \\
\text { pobres; }\end{array}$ & $\begin{array}{l}\text { - os tipos de participantes são } \\
\text { estabelecidos por regras legais e } \\
\text { administrativas federais; } \\
\text { - grupos sociais diretamente } \\
\text { interessados na área de política } \\
\text { pública a qual o conselho é } \\
\text { afeto; }\end{array}$ \\
\hline $\begin{array}{l}\text { Tipos de questões sobre as } \\
\text { quais tomam decisões }\end{array}$ & $\begin{array}{l}\text { - orçamentárias referentes a } \\
\text { gastos de capital e, por vezes, } \\
\text { despesas correntes em todas as } \\
\text { áreas de políticas públicas; }\end{array}$ & $\begin{array}{l}\text { - o tipo de agenda e as questões } \\
\text { sobre as quais podem decidir são } \\
\text { modeladas pelas regras pré-es- } \\
\text { tabelecidas e pelos necessidades } \\
\text { da área de política pública a qual } \\
\text { o conselho é afeto; }\end{array}$ \\
\hline $\begin{array}{l}\text { Regras que guiam sua forma de } \\
\text { funcionamento }\end{array}$ & $\begin{array}{l}\text { - regras de funcionamento } \\
\text { são, em geral, estabelecidas ao } \\
\text { início de cada processo anual } \\
\text { - a agenda de debates e o } \\
\text { cronograma de atividades } \\
\text { publicizados ao início do } \\
\text { processo; } \\
\text { - combina participação direta } \\
\text { e indireta; } \\
\text { - sua organização é apoiada e, } \\
\text { geralmente, coordenada pelo } \\
\text { governo; } \\
\text { - sucessão de encontros: } \\
\text { 10 estabelecem as regras de } \\
\text { funcionamento, as prioridades } \\
\text { e elegem delegados para os } \\
\text { níveis superiores de decisão; } \\
2^{2} \text { delegados de distritos ou } \\
\text { regiões decidem prioridades e, } \\
\text { depois, verificam se o que foi } \\
\text { acordado foi cumprido; } \\
\text { - votaçôes podem ser abertas } \\
\text { par delegados ou mesmo para } \\
\text { os eleitores; } \\
\text { - existem momentos em que } \\
\text { os participantes tem o direito a } \\
\text { voz para expressar preferências. }\end{array}$ & $\begin{array}{l}\text { - regras gerais são estabe- } \\
\text { lecidas por lei ou normas } \\
\text { administrativas federais, mas o } \\
\text { do funcionamento do fórum é } \\
\text { estabelecido pelos regimentos } \\
\text { internos de cada conselho; } \\
\text { - a agenda de debates depen- } \\
\text { de da dinâmica política setorial, } \\
\text { as ações dos gestores de cada } \\
\text { área vão construindo as pautas; } \\
\text { - participação indireta, através } \\
\text { de representação; } \\
\text { - a maioria tem encontros } \\
\text { regulares; } \\
\text { - em geral, têm núcleos de } \\
\text { coordenação formados por } \\
\text { conselheiros, alguns têm supor- } \\
\text { te administrativo e técnico; } \\
\text { - predominam as decisões } \\
\text { por consenso, mas, por vezes, } \\
\text { existem intensas discussões } \\
\text { que podem levar a votações, } \\
\text { especialmente nos conse- } \\
\text { lhos municipais das cidades } \\
\text { maiores, das capitais, estaduais } \\
\text { e federais. }\end{array}$ \\
\hline
\end{tabular}


Sociologias, Porto Alegre, ano 12, no 24, mai./ago. 2010, p. 44-75

\section{Considerações finais}

O presente artigo examinou duas vertentes de interpretação sobre o papel institucional de fóruns participativos que consideram essas experiências como avanços na formas de governança da gestão pública. Além disso, procurou verificar sua adequação para a análise dos mecanismos de participação mais disseminados no Brasil, quais sejam: os orçamentos participativos e os conselhos de políticas públicas. Uma parcela desses estudos argumenta que as experiências participativas brasileiras se constituem em arenas públicas nas quais se expressam os interesses gerais que são trazidos ao debate pelos movimentos sociais. Outra corrente de interpretação considera que os fóruns são mecanismos neocorporativos de representação de interesses particulares, os quais até então nunca haviam sido representados publicamente frente aos governos.

Ao analisar os dois tipos de fóruns participativos abordados, sugerimos que a primeira vertente de estudos é mais adequada para a compreensão dos orçamentos participativos e a segunda para os conselhos de políticas públicas. Isso pode ser explicado pelas características específicas de cada um deles.

No caso do orçamento participativo, é perceptível a constituição de um espaço público para o qual as restrições de acesso são relativamente pequenas e os cidadãos debatem e deliberam problemas da coletividade com relativa autonomia em relação aos governos. As deliberações, assim produzidas, são encaminhadas ao Estado com a expectativa de que venham a ser executadas num espaço de tempo adequado. Sabe-se que, na prática, a dinâmica dos orçamentos participativos não é tão virtuosa, inclusive porque a participação governamental não ocorre a partir de uma posição simétrica à dos representantes da sociedade civil, mas, sim desde uma condição hierarquicamente superior, fundada no acesso diferenciado a diversos recursos de poder. No entanto, isso não interfere no fato 
desta ser uma instância deliberativa com relativa autonomia em relação aos governos, um espaço de incorporação de demandas e proposições dos diferentes atores que integram a sociedade civil, transferindo práticas e informações da esfera societal para a governamental.

Surpreendentemente, a relativa autonomia na constituição de desenhos institucionais e regras de funcionamento - que permitem que modos de ação e de informações transfiram-se da sociedade civil aos governos - depende quase que exclusivamente de um ato de vontade do governante. Isso porque não existe arcabouço legal que fundamente a existência de orçamentos participativos, uma vez que a elaboração de propostas orçamentárias é definida constitucionalmente como prerrogativa de Poder Executivo. Mesmo assim, a inexistência de regras legais não impede a constituição de regras de fato, que podem institucionalizar o fórum, desde que o ambiente político assim o permita. Este parece ser o caso de Porto Alegre, onde governos de orientação político-partidária diferentes têm mantido o Orçamento Participativo em funcionamento.

No caso dos conselhos, dá-se o inverso: as linhas gerais que definem seu papel institucional nas várias áreas de política pública, quem deles pode participar e, principalmente, a própria existência dos fóruns, é definida legalmente. $\mathrm{O}$ acesso aos fóruns não é facultado a todos os cidadãos. Apenas os representantes das organizações designadas por lei, mais frequentemente, ou por decreto do Poder Executivo municipal ou estadual, podem ser considerados como integrantes plenos, com direito à voz e voto. A agenda em discussão é setorial, em geral, sofre forte influência da dinâmica de funcionamento da área de política pública a que estão afetos. Mas esses fóruns permitem que as demandas de usuários e beneficiários de políticas públicas interajam com o Estado, se contrapondo à tendência de autonomia dos gestores. Nesse sentido, representam uma novidade no modo como são tomadas decisões sobre tais políticas no Brasil. 
Sociologias, Porto Alegre, ano 12, no 24, mai./ago. 2010, p. 44-75

Como seus desenhos institucionais são definidos pelo arcabouço legal e administrativo das diversas áreas de políticas públicas, é menor a chance de que a organização de seus trabalhos venha a ser modificada pelos próprios participantes. Assim, mesmo sua autonomia em relação aos governos sendo pequena, ela é ainda maior do que nos orçamentos participativos. Isso porque as regras legais e as normas administrativas que sustentam sua existência e delineiam seus modos de funcionamento, acarretam custos políticos altos para aqueles que não as seguirem - ações do Ministério Público, perda de recursos financeiros federais, etc.

Sem dúvida, a institucionalização dos conselhos limita a transferência de práticas e de informações da sociedade civil para o seu interior, definindo que os participantes societais representem grupos de interesses de cada área de política pública. Este é um quesito que funciona com uma maior fluidez no caso dos orçamentos participativos. Porém, é precisamente esta característica a que impede que os governos desconstituam os conselhos e auxilia a explicar o porquê, atualmente, estes organismos estão disseminados em todos os municípios do país, enquanto os orçamentos participativos existem apenas em algumas centenas de cidades.

Para finalizar, gostaríamos de enfatizar que muito ainda devemos avançar na pesquisa sobre os fóruns participativos brasileiros e seus diferentes paradigmas de análise. Com o presente artigo nossa intenção foi a de estimular a polêmica sobre essas questões, tendo em vista a necessidade de fortalecer no meio acadêmico o debate a respeito das novas experiências de inclusão dos cidadãos na gestão pública. 


\title{
Between the neo-corporatist and the deliberative: an inter- pretation of the paradigms in the analysis of the participatory forums in Brazil
}

\begin{abstract}
This article considers the debate on the major paradigms through which are usually examined the proposals to widen the channels of citizen participation in the management of public policies; studies that examine the participatory processes not only from the prism of the "neo-corporatist arrangements," but also through an approach based on the concept of "deliberative democracy." Aiming at this goal, this paper emphasizes the history of two of the main participatory instances that, in recent decades, have been developed in Brazil: the participatory budgeting and the public policy councils. These instances were evaluated taking into account four aspects in particular: a) institutional relationships with the government; b) the profile of the participants; c) the decision-making context; and d) the functioning dynamics. Considering the study of these characteristics, the authors discuss the ability of the neo-corporatist and the deliberative paradigms to create a consistent analytical model for the investigation of divergent participatory structures.

Keywords: Public Policy Councils. Deliberative democracy. Participatory budgeting. Neo-corporatism.
\end{abstract}

\section{Referências}

ALMEIDA, Maria Herminia Tavares. Sindicatos em tempo de reformas. São Paulo em Perspectiva, v. 12, n. 1, 1998, p. 3-9.

AVRITZER, L. Um desenho institucional para o novo associativismo. Lua Nova, $\mathrm{n}$. 39, 1997, p. 149-151. 25-46.

. Teoria democrática e deliberação pública. Lua Nova, n. 50, 2000, p.

AZEVEDO, Sérgio; ABRANCHES, M. Conselhos Setoriais o caso da Região Metropolitana de Belo Horizonte. Cadernos Metrópole, n. 7, 2002, p. 41-71.

BAKER, Gideon. Civil society and republican democracy. Paper for Political Studies Association-UK Annual Conference, 10-13 April, London, 2000. 
Sociologias, Porto Alegre, ano 12, no 24, mai./ago. 2010, p. 44-75

BONFIM, Washington L.S.; FERNANDES, A.S.A.; Teorias Democráticas Contemporâneas e o caso Brasileiro Pós-Constituição de 1988. Paper presented at XXVIII Encontro Anual da ANPOCS. ST23. Caxambu, 2004.

BOSCHI, Renato Raul. Decentralization, clientelism, and social capital in urban governing: comparing Belo Horizonte and Salvador. Dados. [on line], v. 42, n. 4, 1999, p. 655-690. Disponível em: <http://www .scielo.br/scielo.php?script=sci arttext\&pid=S0011-52581999000400002\&lng=en\& nrm=iso > . ISSN 0011-5258.

BRASIL. Assembléia Nacional Constituinte, Constituição da República Federativa do Brasil de 05 de Outubro de 1988.

BRASIL. Congresso Nacional, Lei 8.142 de 28 de Dezembro de 1990 - Dispõe sobre a participação da comunidade na gestão do Sistema Único de Saúde - SUS e sobre as transferências intergovernamentais de recursos financeiros na área de saúde e dá outras providências, 1990.

BRASIL. Congresso Nacional, Lei 8.742 de 7 de Dezembro de 1993 - Dispõe sobre a organização da assistência social e dá outras providências, 1993.

BULHÕES, M.G.P. Plano Nacional de Qualificação do Trabalhador no Rio Grande do Sul/Brasil: avanços e limites na participação de atores governamentais e não governamentais. In: MILANI, C.; ARTURI, C.; SOLINÍS, G. (Eds.). Democracia e governança mundial: que regulações para o século XXI? Porto Alegre: UFRGS/ UNESCO, 2002, p. 137-165.

CARVALHO, A.I. Conselhos de saúde, participação social e reforma do Estado. Ciência \& Saúde Coletiva, v. 3, n. 1, 1998, p. 23-25.

CASTRO, M. Helena G. de. Equipamentos sociais e política local no pós-64: dois estudos de caso. Espaço e Debates, n. 24, 1988, p. 67-74.

CODEFAT. Resolução no 80, de 19 de abril de 1995. Altera a Resolução no 63, de 28 de julho de 1994, que estabelece critérios para reconhecimento, pelo CODEFAT, de comissões de emprego constituídas em nível Estadual, do Distrito Federal e municipal, no âmbito do sistema público de emprego, 1995.

CORTES, Soraya M. V. Fóruns participatórios na área de saúde: Teorias do estado, participantes e modalidades de participação. Revista Saúde em Debate, n. 4950, 1995, p. 73-79.

CORTES, Soraya M. V. Arcabouço histórico-institucional e a conformação de conseIhos municipais de políticas públicas. Educar em Revista, n. 25, 2005, p. 143-174.

CORTES, Soraya M. V. Fóruns participativos e governança: uma sistematização das contribuições da literatura In: LUBAMBO, Catia; Coelho, Denilson B.; Melo, Marcus A. (Orgs.), Desenho Institucional e Participação Política: experiência no Brasil contemporâneo. Petrópolis: Vozes, v. 1, 2005, p. 13-32. 
CORTES, Soraya M. V. Orçamento Participativo e Conselhos Municipais de Políticas Públicas e de Direitos na Região Metropolitana de Porto Alegre (RMPA). Relatório de Pesquisa, Porto Alegre, 2005.

COSTA, Sergio. La esfera pública y su mediaciones entre cultura y política: el caso de Brasil. Metapolítica, n. 9, 1999, p. 95-107.

COSTA, Sergio. Movimentos sociais, democratização e a construção de esferas públicas locais. Revista Brasileira de Ciências Sociais [online]. Fev. 1997, v. 12, n. 35. Disponível em: http://www.scielo.br/scielo.php?script=sciarttext\&pid $=$ S0102-690919970003 00008\&lng= en\&nrm=iso. ISSN 0102-6909.

DAGNINO, E. Sociedade civil e espaços públicos no Brasil. In: DAGNINO, E. (Ed.). Sociedade civil e espaços públicos no Brasil. São Paulo: Paz e Terra. 2002, p. 9-15.

DIAS, Marcia R. Entre a representação e a participação política: o debate acerca da institucionalização do orçamento participativo em Porto Alegre. In: MILANI, C.; ARTURI, C.; SOLINÍS, G. (Eds.). Democracia e governança mundial: que regulações para o século XXI?. Porto Alegre, UFRGS/UNESCO, 2002, p. 204-230.

EVANS, Peter. Além da 'Monocultura Institucional': instituições, capacidades e o desenvolvimento deliberativo. Sociologias, jan./jun., n. 9, p. 20-63, 2003.

FARIA, Carlos Pimenta. Idéias, conhecimento e políticas públicas: um inventário sucinto das principais vertentes analíticas recentes. Revista Brasileira de Ciências Sociais, v. 18, n. 51, 2003, p. 21-29.

FARIA, Claudia Feres. Democracia deliberativa: Habermas, Cohen e Bohman. Lua Nova, n. 50, 2000, p. 25-46.

FEDOZZI, Luciano. Orçamento Participativo - Reflexões sobre a experiência de Porto Alegre. Porto Alegre: Tomo Editorial, 1997.

FERREIRA, Ana Luiza S. S. Lages: um jeito de governar. São Paulo: Instituto Polis, 1991.

FIORINA, Morris P. A dark side of civic engagement. In: SKOCPOL, Theda; FIORINA, Morris P. (Eds.). Civic engagement in American democracy. Washington: Brookings/Sage, 1999, p. 395-425.

FUNG, Archon; WRIGHT, Erik O. Deepening democracy: innovations in empowered participatory governance. Politics \& Society, March, v. 29, n. 1, 2001, p. 5-41. GOHN, Maria da G. Conselhos gestores e participação política. São Paulo: Cortez, 2001.

GUGLIANO, Alfredo Alejandro. Mirando hacia el sur. Trayectorias de las democracias participativas em América Latina. Sistema, n. 203-204, mayo, 2008 p. 149-170.

GUGLIANO, Alfredo Alejandro; LOECK, Robson; ORSATO, Andréia ; PEREIRA, André Luis. Processos Participativos e Estratégias de Redistribuição: resgatando 
Sociologias, Porto Alegre, ano 12, no 24, mai./ago. 2010, p. 44-75

o Orçamento Participativo em Pelotas (1984-1985). In: MARQUETTI, Adalmir; PIRES, Roberto; CAMPOS, Geraldo Adriano G. de. (Orgs.). Democracia Participativa e Redistribuição. Análise de experiências de orçamento participativo. São Paulo: Xamã, 2008.

HABERMAS, Jürgen. Direito e Democracia: entre facticidade e validade. v. 2. Rio de Janeiro: Tempo Brasileiro, 1997.

HABERMAS, Jürgen. Três modelos normativos de democracia. Lua Nova, n. 36, 1995, p. 39-54.

IBGE. Perfil dos municípios brasileiros - Gestão pública 2001. IBGE. [on line]. Disponível em: http:// www.ibge.gov.br/homeestatistica/economia/perfilmunic/2001/ default.shtm

KELLER, Wilma. Neo-corporativismo e trabalho: a experiência brasileira recente. São Paulo em Perspectiva, v. 9, n. 4, 1998, p. 73-83.

LAVALLE, Adrián G. Sem pena nem glória: o debate sobre a sociedade civil nos anos 1990. Novos Estudos Cebrap, n. 66, 2003, p. 91-109.

LIPJHART, Arend. Modelos de democracia, formas de gobierno y resultados em 36 países. Barcelona: Ariel, 2000.

LUBAMBO, Cátia; COELHO, Denilson B. Governo e sociedade civil aprendem: o que revela a experiência recente de Participação em Pernambuco? In: LUBAMBO, Cátia; COELHO, Denilson B.; MELO, M. (Eds.). Desenho Institucional e Participação Política. Experiências do Brasil contemporâneo. São Paulo: Vozes, 2005.

MARQUETTI, Adalmir Antonio. Experiências de Orçamento Participativo no Brasil: uma proposta de classificação. In: DAGNINO, Evelina; TATAGIBA, Luciana. (Orgs.). Democracia, Sociedade Civil e Participação. Chapecó: Argos Editora Universitária, 2007.

MALLOY, James M. Social security policy and working class in twentieth-century Brazil. Journal of Interamerican Studies and World Affairs, n. 19, v. 1, 1977, p. 35-59.

MINISTÉRIO DA SAÚDE. Perfil dos conselhos municipais de saúde. [on line]. Available Disponível em: http://portal.saude.gov.br/portal /saude/pesquisaconseIhos.pdf, 2006

MULLER, Pierre; SUREL, Yves. L'analyse des politiques publiques. Paris: Montchrestien, 2002.

NAVARRO, Renato G.; GODINHO, Maria Helena L. Movimentos sociais (populares), conselhos municipal e órgão gestor. Cadernos Metrópole. n. 7, 2002, p. 73-92.

OFFE, Claus. Partidos políticos y nuevos movimientos sociales. Madri: Sistema, 1992.

PINTO, Celi R. J. Espaços deliberativos e a questão da representação. Revista Brasileira de Ciências Sociais, v. 19, n. 54, 2004, p. 97-113. 
PÓLIS. Levantamento das Cidades Brasileiras que Realizaram o Orçamento Participativo (1989 - 2004). Pólis [on line]. Disponível em: http://www.polis.org.br/ download/239.pdf, 2006.

PORTA, Donatella della. Deliberation in Movement: Why and How to Study Deliberative Democracy and Social Movements. Acta Politica, n. 40, 2005, p. 336-350.

PRZEWORSKI, Adam. Democracia y Representación. Revista del CLAD, n. 10, feb., 1998, p. 9-44.

PARÁ. Disponível em: http://www.pa.gov.br/noticia_interna.asp?id_ver $=4811$, 2010.

RAICHELES, R. Esfera pública e conselhos de assistência social. Caminhos da construção democrática. São Paulo: Cortez, 2000.

REDE BRASILEIRA DE ORÇAMENTO PARTICIPATIVO. Disponível em: http:// www.pbh.gov.br/redebrasileiraop/html/historico.htm, 2010.

SANTOS Jr, O.A. Democracia e governo local. Rio de Janeiro: Revan/FASE, 2001.

SANTOS, Boaventura de S.; AVRITZER, L. Introdução: para ampliar o cânone democrático. In: SANTOS, B. S. (Ed.). Democratizar a democracia. Os caminhos da democracia participativa. Rio de Janeiro, Civilização Brasileira. 2002, p. 39-82.

SANTOS, Boaventura de Sousa. Reinventar a democracia: entre o pré-contratualismo e o pós-contratualismo. In: OLIVEIRA, Francisco; PAOLI, Maria Célia. (Orgs.) Os sentidos da democracia. Petrópolis, Vozes, 1999.

SANTOS, Maria Helena de Castro. Which Democracy?: A Conceptual View from the Developing Countries Perspectives. Dados. [on line], v. 44, n. 4, 2001, p. 729-771. Disponível em: <http://www.scielo.br/scielo.php?script=sci arttext\&pid=S0011-5258200100 0400003\&lng=en\&nrm = iso >. ISSN 0011-5258.

SCHMITTER, Philippe C. Still the Century of Corporatism? Review of Politics, v. 36 , n. 1, 1974, p. 85-131.

SCHMIDT, Benício Viero. O Estado, a nova esquerda e o neo-corporativismo. Cadernos CRH, n. 35, jul./dez., 2001, p. 85-105.

SCHNEIDER, Aaron; GOLDFRANK, B. Budget and ballots in Brazil: participatory budgeting from the city to the state. IDS, Working Paper n. 149, Brighton, Institute of Development Studies, 2002.

SOLE, Carlota. El debate corporativismo-neo-corporativismo. Revista Española de Investigaciones Sociológicas, v. 26, n. 84, 1984, p. 9-27.

SOUZA, Celina. Políticas Públicas: uma revisão de literatura. Sociologias, v. 8, n. 16, jul./dez., 2006, p. 20-45. 
Sociologias, Porto Alegre, ano 12, no 24, mai./ago. 2010, p. 44-75

SILVA, Marcelo K. Construção da "participação popular". Análise comparativa de processos de participação social na discussão pública do orçamento em municípios da Região Metropolitana de Porto Alegre/RS. Tese doutorado, Universidade Federal do Rio Grande do Sul, 2001.

SKOCPOL, Theda. Advocates without members: The recent transformation of American civic life. In: SKOCPOL, Theda; FIORINA, Morris P. (Eds.). Civic engagement in American democracy. Washington, Brookings/Sage, 1999, p. 461-509.

SOUZA, Celina. Participatory budgeting in Brazilian cities: limits and possibilities in building democratic institutions. Environment \& Urbanization, v. 13, n. 1, 2001, p. 159-184.

TATAGIBA, L. Os conselhos gestores e a democratização das políticas públicas no Brasil. In: DAGNINO, E. (Ed.). Sociedade civil e espaços públicos no Brasil. São Paulo: Paz e Terra, 2002, p. 47-103.

WERLE, Flávia. O.C. Conselhos Municipais de educação: estudo genético histórico. Cadernos de Pesquisa, n. 103, 1998, p. 123-135.

Recebido: 05/04/2010

Aceite final: 11/04/2010 